\title{
ABERTURA
}

\section{CIDADES VISÍVEIS, CIDADES SENSÍVEIS, CIDADES IMAGINÁRIAS}

As cidades fascinam. Realidade muito antiga, elas se encontram na origem daquilo que estabelecemos como os indícios do florescer de uma civilização: a agricultura, a roda, a escrita, os primeiros assentamentos urbanos. Nessa aurora do tempo, milênios atrás, elas lá estavam, demarcando um traçado, em formato quadrado ou circular; definindo um espaço construído e organizado, logo tornado icônico do urbano - torres, muralhas, edifícios públicos, praças, mercados, templos; a exibir sociabilidades complexas e inusitadas na aglomeração populacional que abrigavam; a ostentar a presença de um poder regulador da vida e de outro ordenador do além, na transcendência do divino.

Mas, sobretudo, a cidade foi, desde cedo, reduto de uma nova sensibilidade. Ser citadino, portar um ethos urbano, pertencer a uma cidade implicou formas, sempre renovadas ao longo do tempo, de representar essa cidade, fosse pela palavra, escrita ou falada, fosse pela música, em melodias e canções que a celebravam, fosse pelas imagens, desenhadas, pintadas ou projetadas, que a representavam, no todo ou em parte, fosse ainda pelas práticas cotidianas, pelos rituais e pelos códigos de civilidade presentes naqueles que a habitavam. Às cidades reais, concretas, visuais, tácteis, consumidas e usadas no dia-a-dia, corresponderam outras tantas cidades imaginárias, a mostrar que o urbano é bem a obra máxima do homem, obra esta que ele não cessa de reconstruir, pelo pensamento e pela ação, criando outras tantas cidades, no pensamento e na ação, ao longo dos séculos.

Cidades sonhadas, desejadas, temidas, odiadas; cidades inalcançáveis ou terrivelmente reais, mas que possuem essa força do imaginário de qualificar o mundo. Tais representações foram e são capazes de até mesmo se imporem como as 'verdadeiras', as 'reais', as 'concretas' cidades em que vivemos. Afinal, o que chamamos de 'mundo real' é aquele trazido por nossos sentidos, os quais nos permitem compreender a realidade e enxergá-la desta ou daquela forma. Pois o imaginário é esse motor de ação do homem ao longo de sua existência, é esse agente de atribuição de significados à realidade, é o elemento responsável 
pelas criações humanas, resultem elas em obras exeqüíveis e concretas ou se atenham à esfera do pensamento ou às utopias que não realizaram, mas que um dia foram concebidas.

Muito se tem escrito sobre cidades, mas sua apropriação como tema, pelos historiadores, não é assim tão recuada no tempo.

São antigas, contudo, as chamadas 'histórias de cidades', muitas delas feitas 'de encomenda', em que alguém é convocado a escrever e se dispõe a reunir dados sobre uma urbe e a ordená-los, dando a ver um tempo de origens, um acontecimento fundador, acrescido da poesia de uma lenda, por vezes, e freqüentemente de uma saga ocorrida nas épocas mais recuadas, realizada pelo povo fundador guiado por suas lideranças. Nessa linha ascensional desde o passado até o presente da cidade, constrói-se o desfile ou a evolução cronológica dos governos municipais com seus momentos marcantes e suas realizações fundamentais. Nada muito diferente, enfim, de uma história política de viés tradicional ou de um kit identitário aplicado à evolução de um núcleo urbano. Tais histórias de cidades são antigas, continuam a existir nos tempos atuais, e delas se valem os historiadores até hoje, à cata de algum dado especial, que complemente sua pesquisa nos arquivos...

Poderíamos, talvez, entender tais histórias urbanas como escritas a partir de uma perspectiva quantitativa e evolutiva, ou seja, pertencendo a um tipo de abordagem sem qualquer outro compromisso teórico maior, empenhadas na descrição do crescimento de uma cidade, retraçando a sua evolução desde o passado até o presente, arrolando dados, nomes e fatos, retraçando sua transformação urbanística, dando a ver as mudanças sofridas pela urbe. Informativas, tais histórias de cidades não estabelecem reflexões maiores sobre o fenômeno da urbanização em si, o que não ocorre dentro de outras abordagens realizadas, como aquelas de conotação marxista.

Mesmo sem se intitularem, especificamente, como 'histórias urbanas', estudos de boa qualidade foram feitos no Brasil ao longo das décadas de 1960, 1970 e 1980, na linha de uma história econômico-social com inspiração no materialismo histórico. Tais estudos, por certo, não fizeram da cidade seu objeto de análise, sendo este, preferencialmente, o processo de acumulação de capital e da formação da força de trabalho ou, ainda, da 'desescravização' do país e da contribuição dos imigrantes estrangeiros na formação de um mercado de trabalho livre.

Entretanto, é inegável que, nesse enquadramento problemático a cidade era 'o lugar onde as coisas aconteciam', fosse pelo desenvolvimento daquelas forças capitalistas, fosse pela expansão de um mercado de trabalho nos maiores centros urbanos, para onde acorriam os egressos do regime escravista, ou 
fosse ainda por um processo mais amplo, de modernização e de redefinição das relações entre o campo e a cidade. Segundo essa postura, as cidades compareciam como o locus da acumulação de capital, como o epicentro da transformação capitalista do mundo.

Assim, a cidade era abordada com base em sua dimensão espacial, mas vista através de um processo econômico-social preciso: ela era o território onde se realizava um processo de produção do capital e onde se produziam as relações capitalistas e, por força da opção teórica, onde se enfrentavam as classes sociais e se podia apreciar o processo de dominação/subordinação em curso.

Como resultado de tais estudos, revelou-se a emergência de um fenômeno urbano revelado na complexidade das transformações econômicas havidas e no dinamismo de seus grupos sociais, sobretudo abordado de um ângulo classista, a enfocar a burguesia e o operariado. A cidade era, pois, cenário desse processo, onde se apresentava também a renovação da esfera estatal e das formas de ação política, no bojo de também novos movimentos sociais urbanos.

E, sobre tal espaço privilegiado de transformação econômico-social, criou-se um campo de pesquisa e discussão interdisciplinar, trabalhando sobre a cidade não só historiadores como geógrafos, sociólogos, economistas, urbanistas e antropólogos. A solidez da pesquisa de tais estudos permitiu que se constituísse um enquadramento adequado para compreender a transformação urbana ocorrida no país a partir da segunda metade do século XIX.

Ao longo da década de 1990, a emergência de uma história cultural veio proporcionar uma nova abordagem ao fenômeno urbano. O que cabe destacar no viés de análise introduzido pela história cultural é que a cidade não é mais considerada só como um locus privilegiado, seja da realização da produção, seja da ação de novos atores sociais, mas, sobretudo, como um problema e um objeto de reflexão, a partir das representações sociais que produz e que se objetivam em práticas sociais.

Sabemos, por certo, como já se assinalou no início deste ensaio, que a cidade é, sobretudo, uma materialidade erigida pelo homem, é uma ação humana sobre a natureza. A cidade é, nesse sentido, um outro da natureza: é algo criado pelo homem, como uma sua obra ou artefato. Aliás, é pela materialidade das formas urbanas que encontramos sua representação icônica preferencial, seja pela verticalidade das edificações, seja pelo perfil ou silhueta do espaço construído, seja ainda pela malha de artérias e vias a entrecruzar-se em uma planta ou mapa. Pela materialidade visível, reconhecemos, imediatamente, estar em presença do fenômeno urbano, visualizado de forma bem distinta da realidade rural. 
Mas a cidade, na sua compreensão, é também sociabilidade: ela comporta atores, relações sociais, personagens, grupos, classes, práticas de interação e de oposição, ritos e festas, comportamentos e hábitos. Marcas, todas, que registram uma ação social de domínio e transformação de um espaço natural no tempo. A cidade é concentração populacional, tem um pulsar de vida e cumpre plenamente o sentido da noção do 'habitar', e essas características a tornam indissociavelmente ligada ao sentido do 'humano': cidade, lugar do homem; cidade, obra coletiva que é impensável no individual; cidade, moradia de muitos, a compor um tecido sempre renovado de relações sociais.

É por isso que, ao lado das imagens icônicas da materialidade urbana, há toda uma outra linha de representação que exibe a cidade através da sua população, com suas ruas movimentadas, o povo a habitá-la, a mostrar sua presença e também a sua diversidade, em imagens ora ternas, ora terríveis de contemplar... Mesmo as 'cidades fantasmas' - aquelas de onde a população retirou-se pelos efeitos da guerra, dos movimentos da história ou de catástrofes naturais - são reconhecíveis para nós como 'cidades' porque guardam as marcas, as pegadas, a alma — talvez possamos dizer — daqueles que um dia as habitaram.

Mas a cidade é, ainda, sensibilidade, com o que retornamos ao início deste texto. Cidades são, por excelência, um fenômeno cultural, ou seja, integradas a esse princípio de atribuição de significados ao mundo. Cidades pressupõem a construção de um ethos, o que implica a atribuição de valores para aquilo que se convencionou chamar de urbano.

A cidade é objeto da produção de imagens e discursos que se colocam no lugar da materialidade e do social e os representam. Assim, a cidade é um fenômeno que se revela pela percepção de emoções e sentimentos dados pelo viver urbano e também pela expressão de utopias, de esperanças, de desejos e medos, individuais e coletivos, que esse habitar em proximidade propicia.

É, sobretudo, essa dimensão da sensibilidade que cabe recuperar para os efeitos da emergência de uma história cultural urbana: trata-se de buscar essa cidade que é fruto do pensamento, como uma cidade sensível e uma cidade pensada, urbes que são capazes de se apresentarem mais 'reais' à percepção de seus habitantes e passantes do que o tal referente urbano na sua materialidade e em seu tecido social concreto.

Sem dúvida, essa cidade sensível é uma cidade imaginária construída pelo pensamento e que identifica, classifica e qualifica o traçado, a forma, o volume, as práticas e os atores desse espaço urbano vivido e visível, permitindo que enxerguemos, vivamos e apreciemos desta ou daquela forma a realidade tangível. A cidade sensível é aquela responsável pela atribuição de sentidos e 
significados ao espaço e ao tempo que se realizam na e por causa da cidade. É por esse processo mental de abordagem que o espaço se transforma em lugar, ou seja, portador de um significado e de uma memória; que passamos a considerar uma cidade como metrópole, realidade urbana que, desde o seu surgimento, causou uma revolução na vida, no tempo e no espaço; que criamos as categorias de cidadão e de excluído para expressar as diferenças visíveis e perceptíveis no contexto urbano fazendo com que se criem novas identidades a partir do gesto, do olhar e da palavra que qualifica; que falamos de progresso ou de atraso, que distinguimos o velho do antigo; que construímos a noção de patrimônio e instauramos ações de preservação, ou, em nome do moderno, que redesenhamos uma cidade, destruindo para renovar. São ainda os processos mentais de representação da realidade que nos permitem inventar o passado e construir o futuro, estabelecer as distinções entre rural e urbano, classificar idéias e práticas como modernas ou arcaicas, e considerar certas cidades como turísticas, rentáveis, sustentáveis.

Assim, no desdobramento das abordagens que se fazem sobre o fenômeno urbano no final do século XX e no início do novo século, não se estudam apenas processos econômicos e sociais que ocorrem na cidade, mas as representações que se constroem na e sobre a cidade, ou seja, com o imaginário criado sobre ela. Em outras palavras, os estudos de uma história cultural urbana se aplicam no resgate dos discursos, imagens e práticas sociais de representação da cidade. E o imaginário urbano, como todo o imaginário, diz respeito a formas de percepção, identificação e atribuição de significados ao mundo, o que implica dizer que trata das representações construídas sobre a realidade — no caso, a cidade.

Cidades visíveis, cidades sensíveis, cidades imaginárias. Essa abordagem oferece um variado campo de investigação ao historiador. Cidades são, antes de tudo, cronotopos, para usar a consagrada expressão de Mikhail Bakhtin: elas são unidades de tempo e espaço. Todas essas construções imaginárias de sentido que se estabelecem com relação à cidade são históricas, datadas, o que, em última análise, implica dizer que sempre se dão em uma temporalidade e uma espacialidade determinada.

A cidade é sempre um lugar no tempo, na medida em que é um espaço com reconhecimento e significação estabelecidos na temporalidade; ela é também um momento no espaço, pois expõe um tempo materializado em uma superfície dada.

Porém, em termos de cidade, esse tempo contado se dá sempre a partir de um espaço construído, e não é possível pensar um sem o outro. Quando 
se trata de representificar a memória — ou a história — de uma cidade, a experiência do tempo é indissociável da sua representação no espaço.

A cidade sempre se dá a ver, pela materialidade de sua arquitetura ou pelo traçado de suas ruas, mas também se dá a ler, pela possibilidade de enxergar, nela, o passado de outras cidades, contidas na cidade do presente. Assim, o espaço construído se propõe como uma leitura no tempo, em uma ambivalência de dimensões que se cruzam e se entrelaçam.

Como historiadores, temos a tendência de buscar as cidades do passado que cada urbe abriga, em palimpsesto, e que devem ter deixado traços para serem recuperados mediante um trabalho de pesquisa. A rigor, todo historiador sabe que as marcas de historicidade deixadas no tempo se revelarão diante de si como fontes, a partir da pergunta que ele fará ao passado, questão esta iluminada pelos conceitos que presidem nossa posição diante do real.

Ora, no caso da cidade passada, por vezes esses rastros - para usar a feliz expressão de Ricoeur ${ }^{1}$ - nem sempre estão aparentes, como pegadas a guiar os passos e o olhar do historiador. Com freqüência, a transformação do espaço foi de tal ordem, a modernidade implantada tão avassaladora que apagou do espaço materialidades e sociabilidades do passado. E, como de praxe, o objeto da atenção do historiador passa por fora da experiência do vivido, nessa tarefa de resgate das representações da cidade passada que se produz por uma reconfiguração temporal — como mais uma vez assinala Paul Ricoeur - , construído pela força do imaginário, que é capaz de dar a ver e ler a temporalidade transcorrida.

Ligada a esse processo, a própria natureza das fontes se amplia, em leque, oferecendo ao historiador possibilidades cada vez maiores de abordagem. A rigor, dependendo da pergunta dirigida ao passado para recuperar as cidades de um outro tempo, não há limites para a descoberta das marcas de historicidade.

Mas essa cidade do passado é sempre pensada através do presente, que se renova continuamente no tempo do agora, seja através da memória/evocação, individual ou coletiva, seja através da narrativa histórica pela qual cada geração reconstrói aquele passado. É ainda nessa medida que uma cidade inventa seu passado, construindo um mito das origens, recolhendo as lendas, descobrindo seus pais ancestrais, elegendo seus heróis fundadores, identificando um patrimônio, catalogando monumentos, atribuindo significados aos lugares e aos personagens, definindo tradições, impondo ritos. Mais do que isso, tal processo imaginário de invenção da cidade e de escrita de sua história é capaz de construir utopias, regressivas ou progressivas, através das quais a urbe sonha a si mesma. 
Assim, cada cidade é um palimpsesto de histórias contadas sobre si mesma, que revelam algo sobre o tempo de sua construção e quais as razões e as sensibilidades que mobilizaram a construção daquela narrativa. Nesse curioso processo de superposição de tramas e enredos, as narrativas são dinâmicas e desfazem a suposta imobilidade dos fatos. Personagens e acontecimentos são sucessivamente reavaliados para ceder espaços a novas interpretações e configurações, dando voz e visibilidade a atores e lugares.

Ao inventar o passado, contando a história de suas origens e de seu percurso no tempo para explicar seu presente, a cidade constrói seu futuro, através de projetos e visões de mundo que apontam para um depois, seja como ficção científica, seja como planejamento urbano. A modernidade urbana propicia pensar tais tipos de representação: aqueles referentes aos planos e utopias construídas sobre o futuro da cidade, inscrevendo uma cidade sonhada e desejada em projetos urbanísticos. Realizados ou não, eles são a inscrição de uma vontade e de um pensamento sobre a cidade e, logo, são matérias da história, porque fazem parte da capacidade imaginária de transformar o mundo. Assim como pensa o seu futuro, a cidade inventa o seu passado, sempre a partir das questões do seu presente.

Nesse processo imaginário de construção de espaço-tempo, na invenção de um passado e de um futuro, a cidade está sempre a explicar o seu presente. Com isso, acaba por definir uma identidade, um modo de ser, uma cara e um espírito, um corpo e uma alma, que possibilitam reconhecimento e fornecem aos homens uma sensação de pertencimento e de identificação com a sua cidade.

De certa forma, entendemos ser essa a questão que apresenta Calvino quando nos diz que é preciso interrogar "os deuses da cidade". ${ }^{2}$ É preciso, diz ele, buscar os elementos comuns que distinguem uma cidade da outra. Tal como os antigos, que buscavam o espírito da cidade invocando os nomes dos deuses que presidiram a sua fundação, os homens modernos precisam exercer uma espécie de despojamento do olhar, identificando, simplificando e reduzindo a multiplicidade de traços que uma cidade oferece para dizer quem é. Como uma máquina que compõe, repõe e readapta suas funções, ou como um organismo que, num mesmo espaço, carrega consigo e reatualiza relíquias de um outro tempo, a cidade precisa ser descoberta pelo olhar. Uma cidade se individualiza com relação às outras, ela personifica atitudes e modos de existir, dos homens e do meio ambiente, transformando-se no tempo, alterando a superfície do seu espaço, mas, apesar de todas as transformações que, inexoravelmente sofre, uma cidade deve encontrar seus deuses. 
No entanto, muitas cidades convivem em uma mesma cidade, já alertara Calvino em sua poética e já clássica obra. ${ }^{3}$

Mas como chegar às cidades visíveis do passado, ou às cidades invisíveis, quando o passado sonhava o seu futuro, senão a partir das marcas de historicidade deixadas, que funcionam como pegadas ou rastros para o historiador do presente? Nesse domínio, estamos diante de um vasto material, à disposição de um olhar e de uma questão a ser formulada pelo historiador para que eles se tornem detentores de significados e sejam elevados à categoria de fontes.

Principiemos, talvez, por aquelas formas de representação mais íntimas ao trabalho do historiador: o discurso traduzido em texto. Sim, pois esse é o tradicional terreno do historiador, que busca nas fontes escritas suas marcas de historicidade preferenciais. O historiador é, por definição, um homem de texto, e seu produto, a história, como bem se sabe, é uma narrativa sobre o passado.

As cidades foram, desde há muito, objeto de variadas escritas, desde aquelas que se intitulavam histórias ou crônicas de uma urbe e que, portanto, tinham estatuto de veracidade, por construírem uma narrativa do acontecido, de um passado ou de um presente de uma cidade, até as obras de caráter literário, a celebrarem ou condenarem o urbano em prosa e verso.

Ao historiador do urbano cabe criar sobre tais narrativas as filigranas de sua análise, exercendo sobre elas uma atitude hermenêutica e resgatando a riqueza da intriga construída e do poder metafórico das palavras empregadas. $\mathrm{Ou}$, ainda, cabe divisar os artifícios da ficção, justo naquela narrativa que se arvora em termos de veracidade, a mostrar que todo discurso sobre a cidade é uma recriação de tempo e espaço dotada de sentido. Mesmo proclamando ciência, o discurso histórico contém uma poética e se vale de recursos literários. E, nesse sentido, as fronteiras entre as narrativas histórica e literária se revelam mais porosas ou tênues, o que sem dúvida enriquece a leitura de uma cidade...

Quem duvidaria, por exemplo, da capacidade de um Balzac, Zola, Maupassant, Eça de Queirós, Charles Dickens, Lima Barreto ou Machado de Assis para falar de suas cidades pela via literária? As tramas são imaginadas, os personagens são fictícios, mas o universo do social e a sensibilidade de uma época se revelam diante do leitor de maneira verossímil, convincente. Uma explicação da realidade, realista ou cifrada, realiza-se em comunhão entre o mundo da escrita e o da leitura. Poder-se-ia pensar uma Paris da belle époque, por exemplo, sem que o mundo de Proust fosse ativado? Ou uma São Petersburgo dos czares sem a escrita de Dostoiévski ou Tolstói? E, no terreno da poe- 
sia, como não invocar a Paris por Baudelaire, a Buenos Aires por Jorge Luís Borges ou a Porto Alegre por Mário Quintana?

Mas para a recuperação de uma cidade há que ter em conta, ainda, essas narrativas de fronteira entre o documental e a ficção que são as crônicas de jornal que falam do urbano, ou os discursos de memórias que recompõem no tempo presente reminiscências e experiências passadas, contando as cidades do passado que as cidades de hoje encerram. Seria impensável mergulhar nos valores, nas maneiras, no proceder de uma época sem ter em conta cronistas como João do Rio ou Bilac, para a Capital Federal de 1900.

Como não recorrer também aos diários e relatos de viagens, em que as sensações são registradas e os detalhes anotados, dando ao leitor de hoje a expressão do olhar de um outro no passado, visitante, viajante e passante de uma urbe determinada? E, nesse ponto, temos olhares estrangeiros que adotam, como marcos de referência para o urbano, outras cidades, outros ethos, outros ícones para avaliar uma cidade. Por vezes cruéis, por vezes deslumbrados, esses olhares que revelam uma alteridade contrastante fizeram parte da construção de uma identidade nacional. Pois, como bem sabemos, um pouco do que somos está escrito, de forma estereotipada, na visão do outro...

Uma cidade é objeto de muitos discursos, a revelar tais modalidades sensíveis de leitura do urbano ou saberes específicos, perpassados pelo lustro da ciência. Falam da cidade, para além da literatura e da história, os discursos médicos, políticos, urbanísticos, policiais e jurídicos, todos carregados de conceitos e princípios de uma cientificidade acentuada, dando a ver o urbano sob um aspecto técnico. Mas tampouco esses discursos deixam de empregar metáforas para qualificar a cidade, partilhando assim, eles também, essa possibilidade de qualificar o mundo e de senti-lo, desta ou daquela forma.

Assim, seja em documentação oficial — os processos-crime, os relatórios de inspeção médica e de higiene, os códices policiais, os prontuários de hospitais e asilos, os projetos de reformulação urbana e os pareceres de juristas - , seja nos comentários dos periódicos, nos artigos e nas crônicas do cotidiano ou nos tão conhecidos 'correios do leitor', os saberes se cruzam e se defrontam, ao tomar a cidade como objeto de preocupação, de elaboração de conceitos e execução de práticas.

Inspirados nas leis e nos preceitos das ciências, à luz das mais recentes teorias e conceitos aplicáveis ao fenômeno urbano, a exibir números, fatos e classificações, tais discursos têm sua contrapartida nos ditos 'saberes populares', fruto de crenças ancestrais e tradições, expressando outras maneiras de enxergar o espaço urbano, seus habitantes e suas práticas sociais. Nessa medida, o povo também identifica, julga, classifica e qualifica espaços, persona- 
gens e ações, vaticinando destinos e promovendo também, por seu lado, movimentos de aceitação e repulsa.

Códigos de valores e noções de honra, por exemplo, podem ser partilhados por elites ou populares em um contexto urbano, ou podem defrontar-se em concepções e normas de conduta irreconciliáveis.

E, para além da palavra escrita, há aquela da oralidade, que implica outra forma de dizer a cidade, através do som e das palavras ditas. Entram em cena, assim, os recursos de uma história oral, recuperando depoimentos e relatos de memória, que retraçam uma experiência do vivido e do possível de ser recuperado pela reminiscência, transmitido no presente para aqueles que não estiveram na cidade do passado. Fala-se e conta-se, então, dos mortos, dos lugares que não mais existem, de sociabilidades e ritos já desaparecidos, de formas de falar desusadas, de valores desatualizados. Traz-se ao momento do agora, de certa forma, o testemunho de sobreviventes de um outro tempo, de habitantes de uma cidade que não mais existe.

Essa é, sem dúvida alguma, uma história de fragmentos, de composição em mosaico. Pouco fiável, dirão alguns, pois aquele que rememora não apenas reconta o que viveu a cada momento evocativo, como lida com o gap inegável existente entre o tempo do vivido e o tempo da narrativa. A história oral de uma cidade é tecida e retecida continuamente. O depoente, no caso, é o senhor do tempo, refazendo o que diz sobre o passado da cidade em cada vez que discorre sobre ele.

Mas tal fenômeno, bem sabem os historiadores, não é específico da oralidade. Pois já não se assinalou que toda história é continuamente reescrita, a cada geração? E que no ato da composição narrativa intervêm ingredientes ficcionais, à semelhança da escrita literária, fazendo que mesmo a mais dedicada escrita da história, apoiada em arquivo e método, seja também ela uma representação do passado? Assim, as cidades escritas e as cidades faladas são, todas elas, cidades imaginárias, que um historiador da cultura busca recuperar.

E, em matéria de som e oralidade, há uma cidade musical que invade nossos sentidos. Música e letra, canção e voz acompanham a vida das cidades e falam delas de forma... irresistível, por certo! Pícaras e burlescas, românticas e melodramáticas, solenes e oficiais, as músicas da cidade nos permitem construir imagens mentais do urbano, algumas mesmo tornadas icônicas, como a de certa cidade maravilhosa.

Neste mundo do som, temos de admitir que a música é, por definição, um agente propulsor de sensibilidade e com alto poder de fixação de significados. Escutar uma canção que se refere a uma cidade implica operações imaginárias de sentido que, de imediato, provocam o reconhecimento e mesmo a 
estereotipia da realidade urbana invocada. Uma cidade cantada se insere na memória, ocupando um lugar no tempo.

Neste inventário de marcas sensíveis de historicidade que falam do urbano há ainda um tipo híbrido de fonte: um gênero que mescla o texto com a sua argumentação expressiva, com a oralidade da fala, com a gestualidade da performance, com o espetáculo do visual. Falamos do teatro, por certo. Como não deixar de aludir às revistas do ano, que exibiam a mais crítica e debochada visão do Rio de Janeiro? Maneiras de ser e de agir, personagens e falas, valores e regras, e também o seu inverso, tudo ali estava, a mostrar ao público as muitas críticas - bem-humoradas - de uma cidade...

Mas as cidades nos chegam, enquanto representação, sobretudo pelas imagens visuais. Já destacamos o poder icônico de referência das imagens para a identificação de uma cidade ou do fenômeno urbano em geral. Mas caberia dizer um pouco mais sobre o poder de retenção das imagens. Principiemos por aludir às imagens mentais, no arquivo de memória que cada um carrega consigo e que é acionado pelo pensamento, mas que permite ver o mundo com a força da imaginação.

Não há memória que se efetive sem o recurso às imagens mentais. O que vemos e que constitui imagem graças ao órgão da visão - a imagem visual, portanto, fruto de um dos sentidos básicos do ser humano - entra de imediato em relação com o museu imaginário que possuímos, e que estabelece relações, sobretudo de analogia, com outras tantas imagens mentais que possuímos. É a partir desse processo interativo que se realiza a percepção, ou seja, a qualificação da imagem observada.

No caso das cidades, o processo é nítido. Contemplar uma cidade pela primeira vez, por exemplo, nos remete a outras tantas cidades que conhecemos, por nossa experiência ou leitura, e das quais possuímos imagens. Ou, no caso da cidade do passado, não mais passível de ser observada, mas cujas imagens se acumulam em cadeia no pensamento, vistas ou imaginadas a partir de nossa bagagem cultural e de experiência de vida. Assim, é possível formar, a partir das cidades visíveis, cidades sensíveis e imaginárias, não experimentadas. Um historiador tout court poderia se indagar que grau de fiabilidade essas cidades do pensamento teriam...

Mas as cidades representadas nas cartas geográficas, nas pinturas e desenhos, ou mesmo as projetadas por urbanistas com vista a serem construídas, também guardam com as cidades concretas laços de aproximação complexos. Aqui e ali, a ousadia da imaginação se combinando ao cálculo e à cientificidade dos procedimentos da execução da imagem; lá e acolá, as exigências do realismo documental a serem desafiadas pela força criativa da estética e da 
sensibilidade. A imagem possui um fio terra com o seu referente, daí ser imagem de algo e não ser aquele 'algo' concreto.

Imagens de cidade são representações, factíveis ou não, baseadas em cidades existentes, e elas descortinam para o historiador um panorama fascinante de rastros do passado. Elas são, todas elas, marcas de uma cidade sensível que um dia se impôs ao olhar, à técnica e às emoções daqueles que as traduziram em imagem.

O caso de Jean-Baptiste Debret, no Rio de Janeiro da primeira metade do século XIX, é neste caso um exemplo admirável, tal como o daqueles que deixaram registros das muitas urbes visitadas ou vividas, na segunda metade do século, através da fotografia, como Terragno, Malta, Ferrez ou Callegari.

A partir do desenvolvimento da fotografia, é bem verdade, a história da fabricação das imagens teve uma alteração significativa. Mesmo considerando a foto como um ato de criação, pelo qual se revela a criação do fotógrafo entendido como artista, ela é resultado de um processo técnico que se interpõe entre a realidade retratada e aquele que aciona a máquina fotográfica. Nesse sentido, a foto é traço do objeto que um dia ali esteve diante do aparelho, como uma marca ou pegada que foi possível captar. Dessa forma, as fotografias e, sobretudo, as de cidades, são dotadas de um valor documental: historiadores delas se apropriam em busca de constatar a presença ou ausência de determinados prédios, o estado das ruas, o trajar dos habitantes, os sinais da modernização urbana — ou a sua falta, captando a vida presente em um momento do tempo, congelado para sempre na imagem que se grava no papel pelo efeito técnico de captação da luz.

Paisagens urbanas encontraram uma outra expressão, documental e ficcional, com a entrada em cena do filme. O cinema recompõe, pela imagem em movimento, a expressão da vida na urbe, metrópole ou pequena cidade, a exibir em composição as facetas da materialidade e da sociabilidade. Cidades antigas, cidades modernas, cidades do futuro, cidades encantadas; o urbano é palco e cenário desse espetáculo de imagem em movimento, som, luz e fala, mas é também objeto de uma reflexão que põe a urbanidade com um centro de reflexão. A obra do homem, expressão máxima da civilização, vai com ele perecer? De Blade runner a Matrix, as imagens em ação fílmica discutem, pela via do fantástico, o futuro do urbano e da própria história.

Finalizando, retornamos àquela característica icônica do perfil das cidades: a sua materialidade, tão bem conhecida. Cidades são pedra, aço, ferro, vidro, barro, equipamento, traçado. Mas cidades de pedra podem ser lidas, já dizia Walter Benjamin, e os procedimentos dessa leitura, que fazem da arqui- 
tetura uma narrativa, são quase os mesmos daqueles do discurso literário, complementava Paul Ricoeur. ${ }^{4}$

Assim, uma história cultural urbana vai se orientar pela possibilidade de ver, na cidade, uma projeção dos imaginários no espaço, como bem assinalou Bronislaw Baczko. ${ }^{5}$ A forma de um edifício, a função a que se destina, o uso que efetivamente dele se fará, a sua inserção na vida de uma cidade e o significado que lhe serão atribuídos são elementos que se apresentam à decifração do simbólico desse espaço construído.

Não gostaria de encerrar com definições já tão banais, de que a cidade é um microcosmo que contém o mundo. Mas estive todo o tempo, nesta discussão sobre a cidade como um objeto privilegiado para o estudo do historiador, a falar e a pensar nos valores da cidade. E estes, se bem entendo, estão situados no âmago da condição humana, na medida em que a cidade possibilitaria uma relação entre o espaço e o tempo na vida de cada um e de todos. $\mathrm{Ou}$, para dizer como Marco Polo ao Gran Khan da China, utilizando as palavras de Ítalo Calvino sobre do que seria feita uma cidade: "das relações entre as medidas de seu espaço e os acontecimentos do seu passado”. 6

Que mais poderia desejar um historiador?

Sandra Jatahy Pesavento

UFRGS

${ }^{1}$ Cf. RICOEUR, Paul. Temps et récit. Paris: Seuil, 1984/6.3v.

${ }^{2}$ CALVINO, Italo. The gods of the city: monumentality and the city. The Harvard Architectural Review, Cambridge, v.4, 1984, p.6.

${ }^{3}$ CALVINO, Ítalo. As cidades invisíveis. São Paulo: Companhia das Letras, 1990.

${ }^{4}$ RICOEUR, Paul. Architecture et narrativité. Urbanisme, n.303, p.44-51, nov-déc., 1998.

${ }^{5}$ Cf. BACZKO, Bronislaw. Les imaginaires sociaux. Paris: Payot, 1984.

${ }^{6}$ CALVINO, Ítalo. As cidades invisíveis, cit., p.14. 